\title{
Long term calcium intake and rates of all cause and cardiovascular mortality: community based prospective longitudinal cohort study
}

\begin{abstract}
Objective To investigate the association between long term intake of dietary and supplemental calcium and death from all causes and cardiovascular disease.

Design Prospective longitudinal cohort study.

Setting Swedish mammography cohort, a population based cohort established in 1987-90.

Participants 61433 women (born between 1914 and 1948) followed-up for a median of 19 years.

Main outcome measures Primary outcome measures, identified from registry data, were time to death from all causes $(n=11944)$ and cause specific cardiovascular disease $(n=3862)$, ischaemic heart disease $(n=1932)$, and stroke $(n=1100)$. Diet was assessed by food frequency questionnaires at baseline and in 1997 for 38984 women, and intakes of calcium were estimated. Total calcium intake was the sum of dietary and supplemental calcium.

Results The risk patterns with dietary calcium intake were non-linear, with higher rates concentrated around the highest intakes $(\geq 1400$ $\mathrm{mg} /$ day). Compared with intakes between 600 and $1000 \mathrm{mg} /$ day, intakes above $1400 \mathrm{mg} /$ day were associated with higher death rates from all causes (hazard ratio 1.40, 95\% confidence interval 1.17 to 1.67 ), cardiovascular disease (1 49, 1.09 to 2.02$)$, and ischaemic heart disease $(2.14,1.48$ to 3.09$)$ but not from stroke $(0.73,0.33$ to 1.65$)$. After sensitivity analysis including marginal structural models, the higher death rate with low dietary calcium intake ( $<600 \mathrm{mg} /$ day) or with low and high total calcium intake was no longer apparent. Use of calcium tablets $(6 \%$ users; $500 \mathrm{mg}$ calcium per tablet) was not on average associated with
\end{abstract}

all cause or cause specific mortality but among calcium tablet users with a dietary calcium intake above $1400 \mathrm{mg} /$ day the hazard ratio for all cause mortality was 2.57 (95\% confidence interval 1.19 to 5.55 ).

Conclusion High intakes of calcium in women are associated with higher death rates from all causes and cardiovascular disease but not from stroke.

\section{Introduction}

Calcium is one of the most abundant minerals in the human body and plays a pivotal role in human physiology. The serum levels of calcium are strictly regulated and an insufficient calcium intake is met by a more efficient intestinal absorption and renal conservation of calcium. Calcium is also mobilised from the skeleton, which can lead to bone loss ${ }^{1}$ and subsequent risk of fractures. Consequently, to prevent fractures in elderly people previous and existing guideline ${ }^{2}$ recommend avoidance of low calcium intake. Fractures are common, especially in women, and are associated with high disability, healthcare costs, and mortality. ${ }^{3}$ Insufficient calcium intakes might also lead to secondary hyperparathyroidism, which is associated with higher mortality. ${ }^{145}$ Supplemental use of calcium has become common, and more than $60 \%$ of middle aged and older women in the United States are regular users of calcium supplements. ${ }^{67}$ Worryingly, three recent reanalyses of randomised trials in women have indicated a higher risk of both ischemic heart disease and stroke with calcium supplements, ${ }^{8-10}$ a pattern not observed in a reanalysis of another randomised trial. ${ }^{11}$ Few cohort studies in women have examined the association between 
dietary and supplemental intake of calcium with risk of cardiovascular incidence and mortality; instead, ${ }^{12-16}$ the focus has been on the incidence of stroke, with both contrary and inconsistent findings. ${ }^{12-14} 16$

We hypothesised that long term intake of low or high calcium increases the risk of cardiovascular mortality. We investigated associations between long term dietary and supplemental intake of calcium with all cause mortality as well as with cardiovascular mortality in a large population based prospective study of Swedish women.

\section{Methods}

\section{The Swedish mammography cohort}

The Swedish mammography cohort was established in 1987-90. All women ( $\mathrm{n}=90303)$ residing in two Swedish counties (Uppsala and Västmanland) and born between 1914 and 1948 received a mailed invitation to a routine mammography screening. Enclosed with this invitation was a questionnaire covering diet (food frequency questionnaire) and lifestyle, which was completed by $74 \%$ of the women. In 1997, a second, expanded questionnaire was distributed to those who were still living in the study area (response rate $70 \%$ ). The study sample with exclusions has been described previously. ${ }^{17}{ }^{18}$ In all, 61 433 women with baseline data (1987-90) and 38984 with data from 1997 were available for analysis in the present study (fig $1 \Downarrow)$.

\section{Outcomes}

Follow-up was through the Swedish cause of death registry. Complete linkage with the register is rendered by the personal identity number provided to all Swedish residents. Since 1952 the National Board of Health and Welfare has collected information on the causes of death for all Swedish residents in the cause of death registry. We used the underlying cause of death in the registry to define the outcomes of death from all causes, cardiovascular disease (international classification of diseases, ninth and 10th revisions; ICD-9 codes 390-459 or ICD-10 codes I00-I99), ischaemic heart disease (ICD-9 codes 410-414 or ICD-10 codes I20-I25), and stroke (ICD-9 codes 430-436 or ICD-10 codes I60-I64).

\section{Dietary assessment}

The food frequency questionnaires have been described previously..$^{17}{ }^{20}$ The participants reported their average frequency of consumption of up to 96 foods and beverages during the past year. For most food items, eight categories for frequency of consumption were provided, ranging from never to three or more times daily. For some commonly consumed foods such as milk, sour milk/yogurt, and cheese, participants could fill in the exact number of servings they consumed daily or weekly. We estimated nutrient intakes by multiplying the consumption frequency of each food item by the nutrient content of age specific portion sizes. Nutrient data were obtained from the Swedish National Food Administration database. ${ }^{21} \mathrm{We}$ adjusted nutrient intakes for total energy intake (7.1 MJ or 1700 kcal, mean in the study population) using the residual method. ${ }^{22}$ To better account for changes in diet during follow-up and to better represent long term dietary intake we treated calcium intake as cumulative average intake. ${ }^{23}$ In the second questionnaire the lifetime use of dietary supplements and multivitamins was reported. In Sweden one calcium dose contains $500 \mathrm{mg}$ if from calcium supplements and $120 \mathrm{mg}$ if from multivitamins. Total calcium intake included supplemental calcium from any source. Even if supplement use was absent in the first food frequency questionnaire (baseline questionnaire), the frequency of calcium containing supplement use (with or without vitamin D) within the cohort during the first years of follow-up was low (6\%), ${ }^{24}$ and this proportion was similar across the whole range of dietary calcium intake. Calcium intake in the 1997 food frequency questionnaire correlated well with estimates from 14 repeated 24 hour recalls over one year $(\mathrm{r}=0.77) .{ }^{25}$ Furthermore, a second validation of calcium intake was carried out with four seven day food records every third month in 104 of the women ( $r=0.72)$. Bland-Altman plots revealed only small systematic errors related to intake level between the methods, and the average difference with $95 \%$ confidence interval between the 1997 food frequency questionnaire and seven day food record was $56.4 \mathrm{mg} /$ day $(95 \%$ confidence interval -4.4 to $108.4 \mathrm{mg} /$ day) — that is, as previously reported, ${ }^{25}$ a tendency of higher estimates for calcium intake with the food frequency method. Similar estimates were achieved for the baseline questionnaire. ${ }^{24}$

\section{Comorbidity and other additional information}

Lifestyle information was obtained from the questionnaires. This information included the use of postmenopausal oestrogen therapy and menopausal status, parity, weight and height, smoking habits, and leisure time physical activity during the past year, with five predefined levels ranging from one hour weekly to more than five hours weekly. Physical activity, collected in the 1997 questionnaire, is valid compared with activity records and accelerometer data. ${ }^{26} \mathrm{We}$ divided educational level into four categories: up to 9 years, 10-12 years, more than 12 years, and other (such as vocational). Diagnosis codes were collated from the national patient registry (ICD codes 8,9 , and 10) to calculate Charlson comorbidity scores. ${ }^{27} 28$ The Charlson comorbidity index predicts the 10 year mortality for a patient who may have a range of comorbid conditions (up to 22 diseases). Each condition is assigned a score of 1 to 6 depending on the risk of dying associated with this condition.

\section{Statistical analysis}

For each participant, follow-up time was accrued from baseline (1987-90) until the first date of death, date of leaving the study regions, or the end of the study period (31 December 2008), whichever occurred first. In secondary analyses we considered time to incidence of cardiovascular disease, ischaemic heart disease, and stroke. To improve the validity of our exposure estimate, we used a calibrated calcium intake obtained by usage of linear regression coefficients between food records (FR) and the food frequency questionnaire (FFQ): $\left(\mathrm{R}_{i \mathrm{FR}}=\alpha_{\mathrm{FR}+} \beta_{\mathrm{FR}} * \mathrm{FFQ} i\right.$, ( $\mathrm{R}$ reported calcium in the food records, $i$ in the individual)). ${ }^{29}$ Using Cox proportional hazards regression we estimated age adjusted and multivariable adjusted hazard ratios and their $95 \%$ confidence intervals for prespecified categories of calcium intake: $<600,600-999,1000-1399$, and $\geq 1400 \mathrm{mg} /$ day. To facilitate comparisons of the estimates we used the same category cut-offs in the analysis of dietary and total calcium intake. We estimated the risk with use of calcium containing supplements from the date of the second questionnaire survey (from 1 January 1998). The proportional hazard assumptions in the Cox models were confirmed graphically by comparing Nelson-Aalen plots. Non-linear trends of risk were additionally analysed using restricted cubic-spline Cox regression. We used four "knots" placed at centiles 5, 35, 65, and 95 of the cumulative average calcium intake. ${ }^{30}$ The reference level was set to $800 \mathrm{mg}$ of calcium, which corresponds to the 
recommended daily intake for Swedish women aged more than 50 years. $^{31}$

To minimise potential bias we used the directed acyclical graph approach to identify a suitable multivariable model. The model included age, total energy and vitamin D intake, body mass index, height (all continuous), educational level ( $\leq 9,10-12,>12$ years, other), living alone (yes or no), use of supplements containing calcium (yes or no), a healthy dietary pattern (fifths), physical activity (five categories), smoking status (never, former, current), and score on the Charlson comorbidity index (continuous, 1-16). ${ }^{27}{ }^{28} \mathrm{~A}$ healthy dietary pattern was defined by using a validated method. ${ }^{32}{ }^{33}$ Briefly, we used factor analysis to derive the dietary pattern empirically. Factor analysis reduces dietary data to a few composite factors (one being a healthy dietary pattern) that describe the eating pattern in the population. Other potential covariates (such as menopausal status; hormone replacement therapy; intakes of total fat, retinol, alcohol, potassium, phosphorous, and protein; nulliparity; and previous fracture of any type) in the multivariable models only marginally changed the relations and were therefore not included in the models. We treated covariates as cumulative averages. ${ }^{28}$ The Markov chain Monte Carlo multiple imputation method was used to impute covariates not assessed in the baseline questionnaire in 1987-90 (for example, smoking habits and physical activity). Restriction to non-missing data did not alter our interpretation of the results (data not shown). Moreover, in an attempt to examine whether calcium supplement use modified the association between dietary calcium intake and mortality, we performed stratified analysis by calcium supplement use (no use, use of any type of calcium containing supplements, and specific use of calcium tablets). Additionally, we estimated the synergy index between dietary calcium intake and calcium tablet use. ${ }^{34}$ We performed sensitivity analysis, limiting the analysis to baseline data using ordinary Cox's regression without time updated information. In an attempt to validate the robustness of the Cox's regression model using information updated over time, we used marginal structural modelling. ${ }^{35}$ The categorical exposure in the marginal structural models was treated as described previously. ${ }^{36} \mathrm{We}$ calculated an additional inverse probability weight for having time varying data, and we gave a weight of zero to those without time varying data.

In addition to ultraviolet radiation and genes, vitamin D intake is a determinant of vitamin D status, ${ }^{37-39}$ and vitamin D insufficiency is related to cardiovascular disease mortality and incidence..$^{40} \mathrm{We}$ therefore investigated effect measure modification between dietary calcium and vitamin D intake by including a product interaction term in the multivariable models and performing likelihood ratio tests of its contribution in nested models. We further calculated the relative excess risk that is due to interaction. ${ }^{34}$ When analysing cause specific mortality, we considered the potential competing risk problem from other causes of mortality ${ }^{41}$ and cumulative incidence curves. ${ }^{42}$ The subhazard ratios were similar to the hazard ratios from the ordinary Cox regression, suggesting no major effect of competing risks, which is also the conclusion drawn after analysis of cumulative incidence curves (data not shown).

The statistical analyses were performed with STATA 11 and SAS, version 9.2.

\section{Results}

Table $1 \Downarrow$ lists the characteristics of the study participants by categories of calcium intake. The average total cumulative calcium intake in the lowest category was $572 \mathrm{mg}$ /day and in the highest was $2137 \mathrm{mg} /$ day. With increasing categories of energy standardised calcium intake, the reported intake for most other nutrients also increased, although alcohol intake tended to decrease. There were small differences in calcium supplement use, comorbidity, educational level, smoking status, and physical activity level between categories of calcium intake.

During a median of 19 years of follow-up and 1094880 person years at risk, 11944 women (17\%) died; of these women, the underlying cause of death was cardiovascular disease in 3862, ischaemic heart disease in 1932, and stroke in 1100.

The highest rates of death from all causes, cardiovascular disease, and ischaemic heart disease but not stroke were observed among those with a dietary calcium intake higher than $1400 \mathrm{mg} /$ day (table $2 \Downarrow$ ). These intakes, compared with dietary intakes between 600 and $1000 \mathrm{mg} /$ day, conferred hazard ratios of 1.40 (95\% confidence interval 1.17 to 1.67 ) for all cause mortality, 1.49 (1.09 to 2.02) for cardiovascular disease mortality, and 2.14 (1.48 to 3.09) for ischaemic heart disease mortality.

After multivariable adjustment, a high total calcium intake was also associated with a higher mortality risk (table 2 ). The shift from a lower to a higher risk with the multivariable model was mainly the consequence of the adjustment for use of calcium containing supplements (see supplementary table 1). In addition, mortality rates were higher among women with an intake below $600 \mathrm{mg} /$ day (table 2). The tendency of a U-shaped association between both dietary and total calcium intake with deaths from all causes, cardiovascular disease, and ischaemic heart disease is also visualised by the pattern of the spline curves in figure $2 \Downarrow$, a pattern that was not apparent for stroke mortality. However, to deal further with possible bias introduced by using time updated information in the models, sensitivity analyses were carried out. Firstly, only baseline data were included, without updating with information from the second questionnaire (see supplementary table 2). This analysis indicated a higher risk of death with high dietary calcium intakes but not with low intakes. Secondly, a causal inference analytical model was used. Although hampered by a lower precision (see supplementary table 3), the results for the high dietary calcium intake level are essentially similar to those obtained by ordinary Cox's regression analysis (table 2 and supplementary table 2) but the estimates for women with low dietary calcium intakes were attenuated. Moreover, mortality estimates for women with both low and high total calcium intakes were attenuated compared with the time dependent Cox regression model.

Calcium containing supplements were used by one fourth (10 $055 / 38984$ ) of the study population in 1997 . The largest source of supplemented calcium was from multivitamins with minerals (120 mg per tablet; $74 \%$ of supplement users). Most women taking calcium tablets were also regular users of multivitamins. The average dietary intake of calcium was similar in calcium supplement users, both at baseline (users reported $6 \mathrm{mg}$ lower dietary calcium intake; $95 \%$ confidence interval -2 to $13 \mathrm{mg}$ ) and at the second investigation in 1997 (users reported $6 \mathrm{mg}$ lower intake; 0 to $13 \mathrm{mg}$ ). Use of calcium containing supplements in 1997 was not associated with death from cardiovascular disease or ischaemic heart disease (see supplementary table 4).

Women who had a high dietary intake of calcium exceeding $1400 \mathrm{mg} /$ day and additionally used calcium supplements had a higher mortality rate than women with a similarly high intake of calcium but without taking supplements (table $3 \Downarrow$ ). Thus, among calcium tablet users (500 mg calcium per tablet), a high dietary calcium intake ( $>1400 \mathrm{mg} /$ day) conferred a multivariable adjusted hazard ratio of 2.57 (95\% confidence interval 1.19 to 
5.55) for all cause mortality compared with a dietary calcium intake of between 600 and $999 \mathrm{mg} / \mathrm{day}$. The same comparison among women with use of any type of calcium containing supplement, yielded a multivariable adjusted hazard ratio of 1.51 ( 0.91 to 2.50$)$, whereas the hazard ratio among non-users of calcium containing supplements was 1.17 (0.97 to 1.41 ).

Thus, among women with a high dietary intake of calcium, the addition of calcium supplements increased the risk of death in a dose dependent fashion. The synergy index for the interaction between a high dietary calcium intake and calcium tablet use was 4.87 (95\% confidence interval 1.11 to 21.32).

Vitamin D intake did not significantly modify the associations between calcium intake and the rate of deaths from all causes, cardiovascular disease, or ischaemic heart disease (results not shown).

\section{Discussion}

In this study of women in the Swedish mammography cohort, a high calcium intake (>1400 mg/day) was associated with an increased rate of mortality, including death from cardiovascular disease. The increase was moderate with a high dietary calcium intake without supplement use, but the combination of a high dietary calcium intake and calcium tablet use resulted in a more pronounced increase in mortality. For most women with lower intakes we observed only modest differences in risk.

\section{Strengths and weaknesses of the study}

Strengths of our study include the population based prospective design, study size, and repeated measurements of calcium intake, as well as a large number of potential covariates. Date and cause of death were traced through national healthcare registries and deterministic record linkage, permitting complete ascertainment of the outcomes. The accuracy of classification of causes of death in the cause of death registry and diagnoses in the national patient registry are high. ${ }^{43}$ Furthermore, we adjusted for several important covariates (for example, smoking, socioeconomic status, physical activity, nutrients other than calcium, educational level, and comorbidity), but residual confounding remains a possible limitation. The lower age adjusted rates of death from all causes and cardiovascular disease among women with a high total calcium intake were largely explained by their use of dietary supplements (table 2), a variable considered in the multivariable models. Other health related covariates, including a healthy diet and level of physical activity contributed to a lesser degree. People who use dietary supplements have, on average, a healthier lifestyle and a lower risk factor profile for cardiovascular disease ${ }^{44}$ and not considering this might distort the risk estimates. Moreover, the low proportion of women who took prescription calcium tablets $(6 \%)$, containing a four times higher dose of calcium than in regular multivitamin dietary supplements, made it difficult to detect modestly strong associations with calcium tablet use specifically. Dietary assessment methods are prone to several limitations, affecting both the precision and accuracy of the measurement. In larger studies, a food frequency questionnaire is used to assess the habitual intake of diet, and a recent review concluded that it was a valid method for assessing dietary mineral intake, particularly for calcium. ${ }^{45}$ The food frequency questionnaire may, to some extent, overestimate calcium intake, ${ }^{25}$ which was also indicated by our validation. A further limitation in our study is the use of age standardised portion sizes and not actual individual portion sizes. By use of our calibrated analysis of calcium intake, we none the less tried to avoid some misclassification of study participants. By using repeated measurements on dietary intake we increased the accuracy of the measurement but may also have introduced bias using time dependent Cox regression models. Indeed, after using only baseline data and also after performing the marginal structural model analyses, we no longer observed an increased mortality for women with low calcium intakes or a high total calcium intake. Without being causally linked to death, a low calcium intake could therefore be viewed as a marker of frailty or a less healthy behaviour associated with a higher mortality. There are, however, also theoretical drawbacks of our causal inference model. It is sensitive to correct model specifications and indeed renders estimates with lower precision than ordinary Cox's regression. ${ }^{46}{ }^{47}$ It is worth emphasising that traditionally obtained estimates, such as those from Cox's regression, would not generally agree with estimates from marginal structural models even when there is no confounding. ${ }^{48}$ Irrespective of analytical approach, the observational study design precludes conclusions about causality, and cautious interpretations of the results are therefore recommended. The results for women with a high calcium intake are, however, compatible with results from previous randomised studies, ${ }^{8-10}$ and by fitting the marginal structural model we obtained similar risk estimates although with wider confidence intervals. Our results might also not apply to people of different ethnic origins or to men.

\section{Strengths and weaknesses in relation to other studies}

Calcium intake in adulthood and all cause mortality in women has not been previously investigated. In an analysis including 387 deaths within the Iowa Women's Health Study cohort ${ }^{15}$ a total calcium intake below $700 \mathrm{mg} /$ day but not above 1400 $\mathrm{mg}$ /day was associated with higher mortality from ischaemic heart disease. Furthermore, a recent reanalysis of the same cohort showed that use of calcium supplements was inversely related to the total and cardiovascular mortality rate, although the benefit was lost at the highest doses of dietary calcium intake. ${ }^{49}$ In contrast, use of calcium supplements in a Finnish cohort increased the risk of cardiovascular disease.$^{50}$ Intriguingly, three reanalyses of randomised trials have consistently shown a higher rate of both myocardial infarction and stroke by $25 \%$ to $30 \%$ and by $15 \%$ to $20 \%$, respectively, with calcium supplementation..$^{8-10}$ These results were not confirmed in a reanalysis of another randomised trial using a broad composite endpoint of different cardiovascular events. ${ }^{11}$ Interestingly, the higher risk of cardiovascular events with calcium supplements in a meta-analysis ${ }^{8}$ was only observed in women with a dietary calcium intake higher than $800 \mathrm{mg} /$ day and not in women with lower intake levels.

The results from the few prospective cohort studies that have examined the relation between calcium intake and incidence of cardiovascular disease in women are contradictory or not conclusive. In the Nurses' Health Study cohort there was a higher risk of stroke in women with a calcium intake below 600 $\mathrm{mg} /$ day. ${ }^{12}$ Similarly, in a Japanese setting with a comparably low average calcium intake, women with an intake below about $500 \mathrm{mg} /$ day had a higher rate of stroke but not of coronary heart disease. ${ }^{13}{ }^{14}$ None the less, calcium intake was not related to stroke incidence in a previous analysis in our cohort, ${ }^{16}$ concordant with the results of the present investigation. We have recently shown that calcium intakes above $700 \mathrm{mg} /$ day do not further reduce the risk of fracture and osteoporosis. ${ }^{18}$

Vitamin D enhances, directly or indirectly, renal conservation and intestinal absorption of calcium. ${ }^{51}$ Our results suggest that vitamin D intake did not modify the association of calcium intake and mortality rate. In comparison with exposure to 
ultraviolet radiation and genetic constitution, vitamin $\mathrm{D}$ intake contributes only modestly to vitamin D status, ${ }^{37-39}$ which is determined by serum calcidiol levels, a metabolite not measured in the present investigation.

\section{Possible explanations and implications}

Calcium levels in serum are under tight homeostatic control, and calcium intake is not normally correlated with calcium serum levels. Diets that are low or very high in calcium can, however, override normal homeostatic control causing changes in blood levels of calcium or calciotropic hormones. ${ }^{52}$ Calcium enriched meals can reduce calcitriol, the active vitamin D metabolite, by inhibition of $1 \alpha$ hydroxylase ${ }^{53}$ and also increase serum levels of fibroblast growth factor $23 .{ }^{54}$ Higher levels of circulating fibroblast growth factor 23 are associated with an increased risk of cardiovascular events and all cause mortality. ${ }^{55-57}$ In addition, fibroblast growth factor 23 downregulates calcitriol levels. ${ }^{58}$ Vitamin D suppression leads to an upregulation of the renin-angiotensin-aldosterone system and hypertension, higher levels of proinflammatory cytokines involved in the pathogenesis of atherosclerosis, increased carotid artery intima medial thickness, decreased endothelial function, hypertrophy of cardiac and vascular muscle cells, and a possible increase in serum triglycerides.$^{59}$ Finally, high serum calcium levels can increase the risk of cardiovascular mortality ${ }^{60}$ by induction of a hypercoagulable state. ${ }^{61}$

Our present data together with previous observations suggest that for the prevention of fractures in elderly people ${ }^{18}$ and simultaneous avoidance of possible serious adverse events related to a high calcium intake (such as higher risk of hip fracture, ${ }^{18}{ }^{62}$ cardiovascular disease, ${ }^{63}$ renal stones,${ }^{64}$ and, as observed in the current study, mortality) emphasis should be placed on people with a low intake of calcium rather than increasing the intake of those already consuming satisfactory amounts.

\section{Conclusion}

When looking at the totality of our data, high calcium intakes were associated with higher rates of death from all causes and cardiovascular disease. Mortality was not increased between 600 and $1400 \mathrm{mg} /$ day of total calcium intake, the most customary levels of intake in this setting. The suggestion of an increased risk of mortality by a low calcium intake in our study seemed to be biased by time varying confounding factors.

Contributors: KM designed the study, interpreted the data, and drafted the manuscript. LB analysed the data. LB, HM, EWL, and AW contributed to the interpretation of the data and revision of the manuscript. $\mathrm{KM}$ and AW financed the study. All authors had full access to all data (including statistical reports and tables) in the study and take responsibility for the integrity of the data and the accuracy of the data analysis. KM is the guarantor.

Funding: Supported by the Swedish Research Council, grant numbers 2008-2202 and 2009-6281. The funding source was not involved in the design, conduct or interpretation of the study, or in the writing of the submitted work.

Competing interests: All authors have completed the ICMJE uniform disclosure form at www.icmje.org/coi_disclosure.pdf (available on request from the corresponding author) and declare: no support from any organisation for the submitted work; no financial relationships with any organisations that might have an interest in the submitted work in the previous three years; no other relationships or activities that could appear to have influenced the submitted work.
Ethical approval: The study was approved by the regional ethics committee at Karolinska Institutet, Stockholm, Sweden, and all participants gave their informed consent.

Data sharing: No additional data available.

Fraser WD. Hyperparathyroidism. Lancet 2009;374:145-58

2 Ross AC, Manson JE, Abrams SA, Aloia JF, Brannon PM, Clinton SK, et al. The 2011 report on dietary reference intakes for calcium and vitamin $D$ from the Institute of Medicine: what clinicians need to know. J Clin Endocrinol Metab 2011;96:53-8.

3 Rachner TD, Khosla S, Hofbauer LC. Osteoporosis: now and the future. Lancet 2011;377:1276-87.

4 Hagstrom E, Hellman P, Larsson TE, Ingelsson E, Berglund L, Sundstrom J, et al. Plasma parathyroid hormone and the risk of cardiovascular mortality in the community. Circulation 2009;119:2765-71.

5 Peiris AN, Youssef D, Grant WB. Secondary hyperparathyroidism: benign bystander or culpable contributor to adverse health outcomes? South Med J 2012;105:36-42.

6 Gahche J, Bailey R, Burt V, Hughes J, Yetley E, Dwyer J, et al. Dietary supplement use among U.S. adults has increased since NHANES III (1988-1994). NCHS Data Brief $\operatorname{Apr}(61): 1-8$

7 Mangano KM, Walsh SJ, Insogna KL, Kenny AM, Kerstetter JE. Calcium intake in the United States from dietary and supplemental sources across adult age groups: new estimates from the National Health and Nutrition Examination Survey 2003-2006. J Am Diet Assoc 2011;111:687-95.

8 Bolland MJ, Avenell A, Baron JA, Grey A, MacLennan GS, Gamble GD, et al. Effect of calcium supplements on risk of myocardial infarction and cardiovascular events: meta-analysis. BMJ 341:c3691.

9 Bolland MJ, Grey A, Avenell A, Gamble GD, Reid IR. Calcium supplements with or without vitamin $D$ and risk of cardiovascular events: reanalysis of the Women's Health Initiative limited access dataset and meta-analysis. BMJ 2010;342:d2040.

10 Bolland MJ, Barber PA, Doughty RN, Mason B, Horne A, Ames R, et al. Vascular events in healthy older women receiving calcium supplementation: randomised controlled trial. BMJ 2008;336:262-6.

11 Lewis JR, Calver J, Zhu K, Flicker L, Prince RL. Calcium supplementation and the risks of atherosclerotic vascular disease in older women: results of a 5-year RCT and a 4.5-year follow-up. J Bone Miner Res 2011;26:35-41.

12 Iso H, Stampfer MJ, Manson JE, Rexrode K, Hennekens CH, Colditz GA, et al. Prospective study of calcium, potassium, and magnesium intake and risk of stroke in women. Stroke 1999;30:1772-9.

13 Umesawa $\mathrm{M}$, Iso $\mathrm{H}$, Date $\mathrm{C}$, Yamamoto $\mathrm{A}$, Toyoshima $\mathrm{H}$, Watanabe $\mathrm{Y}$, et al. Dietary intake of calcium in relation to mortality from cardiovascular disease: the JACC Study. Stroke 2006;37:20-6.

14 Umesawa M, Iso H, Ishihara J, Saito I, Kokubo Y, Inoue M, et al. Dietary calcium intake and risks of stroke, its subtypes, and coronary heart disease in Japanese: the JPHC Study Cohort I. Stroke 2008;39:2449-56.

15 Bostick RM, Kushi LH, Wu Y, Meyer KA, Sellers TA, Folsom AR. Relation of calcium, vitamin $D$, and dairy food intake to ischemic heart disease mortality among postmenopausal women. Am J Epidemiol 1999;149:151-61.

16 Larsson SC, Virtamo J, Wolk A. Potassium, calcium, and magnesium intakes and risk of stroke in women. Am J Epidemiol 2011;174:35-43.

17 Larsson SC, Bergkvist L, Wolk A. Long-term dietary calcium intake and breast cancer risk in a prospective cohort of women. Am J Clin Nutr 2009;89:277-82.

18 Warensjo E, Byberg L, Melhus H, Gedeborg R, Mallmin H, Wolk A, et al. Dietary calcium intake and risk of fracture and osteoporosis: prospective longitudinal cohort study. BMJ 2011;342:d1473

19 Larsson SC, Bergkvist L, Wolk A. Long-term meat intake and risk of breast cancer by oestrogen and progesterone receptor status in a cohort of Swedish women. Eur J Cancer 2009;45:3042-6.

20 Larsson SC, Bergkvist L, Wolk A. Conjugated linoleic acid intake and breast cancer risk in a prospective cohort of Swedish women. Am J Clin Nutr 2009;90:556-60.

21 Bergström L, Kylberg E, Hagman U, Erikson H, Bruce Å. The food composition database KOST: the National Administration's information system for nutritive values of food. [In Swedish]. Vår Föda 1991;43:439-47.

22 Willett WC, Howe GR, Kushi LH. Adjustment for total energy intake in epidemiologic studies. Am J Clin Nutr 1997;65(4 Suppl):S1220-8; discussion S29-31.

23 Hu FB, Stampfer MJ, Rimm E, Ascherio A, Rosner BA, Spiegelman D, et al. Dietary fat and coronary heart disease: a comparison of approaches for adjusting for total energy intake and modeling repeated dietary measurements. Am J Epidemiol 1999;149:531-40.

24 Michaëlsson K, Melhus H, Bellocco R, Wolk A. Dietary calcium and vitamin D intake in relation to osteoporotic fracture risk. Bone 2003:32:694-703.

25 Messerer M, Johansson SE, Wolk A. The validity of questionnaire-based micronutrient intake estimates is increased by including dietary supplement use in Swedish men. $J$ Nutr 2004; $134: 1800-5$

26 Orsini N, Bellocco R, Bottai M, Hagstromer M, Sjostrom M, Pagano M, et al. Validity of self-reported total physical activity questionnaire among older women. Eur J Epidemiol 2008;23:661-7.

27 Charlson ME, Pompei P, Ales KL, MacKenzie CR. A new method of classifying prognostic comorbidity in longitudinal studies: development and validation. $J$ Chronic Dis 1987;40:373-83.

28 Quan $\mathrm{H}$, Sundararajan V, Halfon $\mathrm{P}$, Fong A, Burnand B, Luthi J, et al. Coding algorithms for defining comorbidities in ICD-9-CM and ICD-10 administrative data. Med Care 2005;43:1130-9.

29 Kaaks R, Ferrari P, Ciampi A, Plummer M, Riboli E. Uses and limitations of statistical accounting for random error correlations, in the validation of dietary questionnaire assessments. Public Health Nutr 2002;5(6A):969-76.

30 STATA. Stata reference manual, release 11. In: Stata Corporation, ed. Stata Press, 2009

31 Anon. Nordic Nutrition Recommendadtions 2004. Integrating nutrition and physical activity . 4th ed. Nordic Council of Ministers, 2004.

32 Newby PK, Tucker KL. Empirically derived eating patterns using factor or cluster analysis: a review. Nutr Rev 2004;62:177-203.

33 Newby PK, Weismayer C, Akesson A, Tucker KL, Wolk A. Long-term stability of food patterns identified by use of factor analysis among Swedish women. J Nutr 2006;136:626-33. 


\section{What is already known on this topic}

A low calcium intake is associated with higher fracture rates in elderly people and a higher risk of stroke and fatal ischaemic heart disease

Meta-analyses of some randomised studies have, however, shown a higher risk of incident ischaemic heart disease and stroke with calcium supplement use

In observational studies, use of calcium supplements has been associated with both lower overall and cardiovascular mortality rate, as well as higher incidence of cardiovascular disease

\section{What this study adds}

In this Swedish cohort study of women, high intakes of calcium (>1400 mg/day) were associated with higher mortality The increase was moderate with a high dietary calcium intake without supplement use, but more pronounced with a high dietary calcium intake with calcium tablet use

For most women with lower calcium intakes only modest differences in risk were observed

34 Andersson T, Alfredsson L, Kallberg $\mathrm{H}$, Zdravkovic S, Ahlbom A. Calculating measures of biological interaction. Eur J Epidemiol 2005;20:575-9.

35 Fewell Z, Hernán MA, Wolfe F, Tilling $\mathrm{K}$, Choi $\mathrm{H}$, Sterne JAC. Controlling for time-dependent confounding using marginal structural models. Stata J 2004;4:402-20.

36 Nandi A, Glymour MM, Kawachi I, VanderWeele TJ. Using marginal structural models to estimate the direct effect of adverse childhood social conditions on onset of heart disease, diabetes, and stroke. Epidemiology 2012;23:223-32.

37 Snellman G, Melhus H, Gedeborg R, Olofsson S, Wolk A, Pedersen NL, et al. Seasonal genetic influence on serum 25-hydroxyvitamin D levels: a twin study. PLoS One 2009;4:e7747.

38 Burgaz A, Akesson A, Oster A, Michaelsson K, Wolk A. Associations of diet, supplement use, and ultraviolet $B$ radiation exposure with vitamin $D$ status in Swedish women during winter. Am J Clin Nutr 2007:86:1399-404

39 McCullough ML, Weinstein SJ, Freedman DM, Helzlsouer K, Flanders WD, Koenig K, et al. Correlates of circulating 25-hydroxyvitamin D: Cohort Consortium Vitamin D Pooling Project of Rarer Cancers. Am J Epidemiol 2010;172:21-35.

40 Swales HH, Wang TJ. Vitamin D and cardiovascular disease risk: emerging evidence. Curr Opin Cardiol 2010;25:513-7.

41 Fine J, Gray R. A proportional hazards model for the subdistribution of a competing risk J Am Stat Assoc 1999;94:496-509.

42 Lin DY. Non-parametric inference for cumulative incidence functions in competing risks studies. Stat Med 1997;16:901-10.

43 Tunstall-Pedoe H, Kuulasmaa K, Amouyel P, Arveiler D, Rajakangas AM, Pajak A. Myocardial infarction and coronary deaths in the World Health Organization MONICA Project. Registration procedures, event rates, and case-fatality rates in 38 populations from 21 countries in four continents. Circulation 1994;90:583-612.

44 Rautiainen S, Åkesson A, Levitan EB, Morgenstern R, Mittleman MA, Wolk A. Multivitamin use and the risk of myocardial infarction: a population-based cohort of Swedish women. Am J Clin Nutr 2010;92:1251-6.

45 Serra-Majem L, Pfrimer K, Doreste-Alonso J, Ribas-Barba L, Sanchez-Villegas A, Ortiz-Andrellucchi $A$, et al. Dietary assessment methods for intakes of iron, calcium, selenium, zinc and iodine. Br J Nutr 2009;102(Suppl 1):S38-55.

46 Suarez D, Borras R, Basagana X. Differences between marginal structural models and conventional models in their exposure effect estimates: a systematic review. Epidemiology 2011;22:586-8.

47 Cole SR, Hernan MA. Constructing inverse probability weights for marginal structural models. Am J Epidemiol 2008;168:656-64.

48 Kaufman JS. Marginalia: comparing adjusted effect measures. Epidemiology 2010;21:490-3.

49 Mursu J, Robien K, Harnack LJ, Park K, Jacobs DR Jr. Dietary supplements and mortality rate in older women: the lowa Women's Health Study. Arch Intern Med 2011;171:1625-33.

50 Pentti K, Tuppurainen MT, Honkanen R, Sandini L, Kroger H, Alhava E, et al. Use of calcium supplements and the risk of coronary heart disease in 52-62-year-old women: the Kuopio Osteoporosis Risk Factor and Prevention Study. Maturitas 2009;63:73-8.
51 Cashman KD. Diet, nutrition, and bone health. J Nutr 2007;137(11 Suppl):S2507-12. 52 Schwartz GG. Is serum calcium a biomarker of fatal prostate cancer? Future Oncol 2009;5:577-80

53 Bushinsky DA, Riera GS, Favus MJ, Coe FL. Evidence that blood ionized calcium can regulate serum $1,25(\mathrm{OH}) 2 \mathrm{D} 3$ independently of parathyroid hormone and phosphorus in the rat. J Clin Invest 1985;76:1599-604.

54 Vervloet MG, van Ittersum FJ, Buttler RM, Heijboer AC, Blankenstein MA, ter Wee PM. Effects of dietary phosphate and calcium intake on fibroblast growth factor-23. Clin J Am Soc Nephrol 2011;6:383-9.

55 Kendrick J, Cheung AK, Kaufman JS, Greene T, Roberts WL, Smits G, et al. FGF-23 associates with death, cardiovascular events, and initiation of chronic dialysis. J Am Soc Nephrol 2011:22:1913-22.

56 Faul C, Amaral AP, Oskouei B, Hu MC, Sloan A, Isakova T, et al. FGF23 induces left ventricular hypertrophy. J Clin Invest 2011;121:4393-408.

57 Mirza MA, Larsson A, Melhus H, Lind L, Larsson TE. Serum intact FGF23 associate with left ventricular mass, hypertrophy and geometry in an elderly population. Atherosclerosis 2009;207:546-51.

58 John GB, Cheng CY, Kuro-o M. Role of Klotho in aging, phosphate metabolism, and CKD. Am J Kidney Dis 2011:58:127-34.

59 Lee JH, O'Keefe JH, Bell D, Hensrud DD, Holick MF. Vitamin D deficiency an important, common, and easily treatable cardiovascular risk factor? J Am Coll Cardiol 2008;52:1949-56.

60 Leifsson BG, Ahren B. Serum calcium and survival in a large health screening program. $J$ Clin Endocrinol Metab 1996:81:2149-53.

61 Reid IR, Bolland MJ, Avenell A, Grey A. Cardiovascular effects of calcium supplementation. Osteoporos Int 2011;22:1649-58.

62 Bischoff-Ferrari HA, Dawson-Hughes B, Baron JA, Burckhardt P, Li R, Spiegelman D, et al. Calcium intake and hip fracture risk in men and women: a meta-analysis of prospective cohort studies and randomized controlled trials. Am J Clin Nutr 2007;86:1780-90.

63 Reid IR, Bolland MJ, Sambrook PN, Grey A. Calcium supplementation: balancing the cardiovascular risks. Maturitas 2011:69:289-95.

64 Jackson RD, LaCroix AZ, Gass M, Wallace RB, Robbins J, Lewis CE, et al. Calcium plus vitamin D supplementation and the risk of fractures. N Engl J Med 2006;354:669-83.

\section{Accepted: 28 December 2012}

\section{Cite this as: BMJ 2013;346:f228}

This is an open-access article distributed under the terms of the Creative Commons Attribution Non-commercial License, which permits use, distribution, and reproduction in any medium, provided the original work is properly cited, the use is non commercial and is otherwise in compliance with the license. See: http://creativecommons.org/licenses/bync/2.0/ and http://creativecommons.org/licenses/by-nc/2.0/legalcode. 


\section{Tables}

Table 1 | Characteristics of participants by categories of average cumulative total intake of calcium. Values are numbers (percentages) unless stated otherwise

\begin{tabular}{|c|c|c|c|c|}
\hline \multirow[b]{2}{*}{ Characteristics } & \multicolumn{4}{|c|}{ Daily total intake of calcium (mg/day) } \\
\hline & $<600$ & $600-999$ & 1000-1399 & $\geq 1400$ \\
\hline Participants & $2058(3.3)$ & $38388(62.5)$ & $19746(32.1)$ & $1241(2.0)$ \\
\hline Mean (SD) age at entry (years) & $54.9(10.3)$ & $53.9(9.8)$ & $53.3(9.5)$ & $53.6(9.3)$ \\
\hline $\begin{array}{l}\text { Mean (SD) body mass index at entry } \\
\left(\mathrm{kg} / \mathrm{m}^{2}\right)\end{array}$ & $24.9(4.3)$ & 24.7 (3.9) & $24.8(3.9)$ & $24.3(3.8)$ \\
\hline \multicolumn{5}{|l|}{ Daily intake*: } \\
\hline Total calcium (mean, mg) & $572(150)$ & $933(142)$ & $1243(206)$ & $2137(565)$ \\
\hline Total calcium (median, mg) & 543 & 859 & 1096 & 1514 \\
\hline Calcium (mean, mg) & $533(66)$ & $840(99)$ & $1088(105)$ & $1244(271)$ \\
\hline Calcium (median, mg) $\dagger$ & 542 & 852 & 1074 & 1260 \\
\hline Calcium supplementation $\dagger$ & $61(16.7)$ & $4054(17.6)$ & $5137(35.4)$ & $803(76.8)$ \\
\hline $\begin{array}{l}\text { Calcium supplement use }(500 \mathrm{mg} \\
\text { calcium/tablet)† }\end{array}$ & $10(2.7)$ & $394(1.7)$ & $1472(10.1)$ & $694(66.4)$ \\
\hline $\begin{array}{l}\text { Calcium containing multivitamin use (120 } \\
\text { mg calcium per tablet) } \dagger\end{array}$ & $54(14.8)$ & $3785(16.4)$ & $4290(29.5)$ & $444(42.5)$ \\
\hline Supplemental calcium (mean, mg)† & $107(81)$ & $122(90)$ & $241(241)$ & $1063(697)$ \\
\hline Vitamin D (mean, $\mu \mathrm{g})$ & $4.1(1.4)$ & $4.3(1.2)$ & $4.7(1.3)$ & $5.1(1.6)$ \\
\hline Vitamin D supplementation $\dagger$ & $54(14.8)$ & $3802(16.5)$ & $4296(29.6)$ & $448(42.9)$ \\
\hline Supplemental vitamin D (mean, $\mu \mathrm{g}) \dagger$ & $0.6(1.6)$ & $0.7(1.8)$ & $1.5(2.6)$ & $2.9(6.4)$ \\
\hline Retinol (mean, $\mu \mathrm{g}$ ) & $930(675)$ & $974(601)$ & $1012(559)$ & $1026(541)$ \\
\hline Potassium (mean, mg) & $2695(528)$ & 3018 (437) & $3253(452)$ & $3421(572)$ \\
\hline Alcohol (mean, g) & $2.7(4.7)$ & $3.0(4.0)$ & $2.8(3.4)$ & $2.9(3.6)$ \\
\hline Protein (mean, g) & $52.4(22.9)$ & $62.6(17.8)$ & $71.0(18.8)$ & $77.4(23.5)$ \\
\hline Total fat (mean, g) & $54.3(10.5)$ & $56.2(8.3)$ & $56.5(8.6)$ & $55.5(9.6)$ \\
\hline Energy (mean, kJ) & $6636(2494)$ & $6778(1891)$ & $6803(1858)$ & $6945(2117)$ \\
\hline \multicolumn{5}{|l|}{ Leisure time physical activity level†ł: } \\
\hline 1 (lowest) & $100(33.8)$ & $4202(20.6)$ & $2425(18.6)$ & $164(17.7)$ \\
\hline 2 & $52(17.6)$ & $4883(24.0)$ & $2975(22.8)$ & $240(25.8)$ \\
\hline 3 & $81(27.4)$ & $6678(32.8)$ & $4552(34.9)$ & $294(31.7)$ \\
\hline 4 & $31(10.5)$ & $2362(11.6)$ & $1587(12.2)$ & $113(12.2)$ \\
\hline 5 (highest) & $32(10.8)$ & $2232(11.0)$ & $1488(11.4)$ & $118(12.7)$ \\
\hline \multicolumn{5}{|l|}{ Smoking status: } \\
\hline Current smoker†‡ & $112(32.2)$ & $5138(22.8)$ & $3330(23.4)$ & $251(24.5)$ \\
\hline Non-smoker†‡ & $66(19.0)$ & $5066(22.5)$ & $3325(23.3)$ & $271(26.5)$ \\
\hline Former smoker†‡ & $170(48.9)$ & $12321(54.7)$ & 7591 (53.3) & $502(49.0)$ \\
\hline \multicolumn{5}{|l|}{ Education: } \\
\hline$\leq 9$ years $\ddagger$ & $1710(84.7)$ & $30543(81.0)$ & $15175(78.3)$ & $928(76.1)$ \\
\hline 10-12 years $\ddagger$ & $123(6.1)$ & $2580(6.8)$ & $1387(7.2)$ & $85(7.0)$ \\
\hline$>12$ years $\ddagger$ & $46(2.3)$ & $1584(4.2)$ & $1114(5.8)$ & $78(6.4)$ \\
\hline Vocational or other $\neq$ & $139(6.9)$ & $3018(8.0)$ & $1708(8.8)$ & $128(10.5)$ \\
\hline Nulliparity & $280(13.6)$ & $4083(10.6)$ & $2021(10.2)$ & $139(11.2)$ \\
\hline Living aloneł & $540(26.4)$ & $8638(22.7)$ & $4877(25.0)$ & $377(30.6)$ \\
\hline \multicolumn{5}{|l|}{ Charlson comorbidity score: } \\
\hline 1 & 285 (13.9) & $4166(10.9)$ & $2121(10.7)$ & $188(15.2)$ \\
\hline$\geq 2$ & $182(8.8)$ & $2978(7.8)$ & $1541(7.8)$ & $109(8.8)$ \\
\hline Fracture before baseline & $93(4.5)$ & $1735(4.5)$ & $951(4.8)$ & $74(6.0)$ \\
\hline
\end{tabular}




\section{Table 1 (continued)}

\begin{tabular}{|c|c|c|c|c|}
\hline \multirow[b]{2}{*}{ Characteristics } & \multicolumn{4}{|c|}{ Daily total intake of calcium (mg/day) } \\
\hline & $<600$ & $600-999$ & $1000-1399$ & $\geq 1400$ \\
\hline Hormone replacement therapy use $\dagger$ & $140(38.4)$ & $10070(43.7)$ & $6801(46.8)$ & $575(55.0)$ \\
\hline Cortisone tablet use†‡ & $38(15.0)$ & $1639(10.4)$ & $1123(11.0)$ & $150(19.5)$ \\
\hline
\end{tabular}

*Energy adjusted cumulative average nutrient data was estimated with data from the 1987 and 1997 questionnaires. tInformation only available in 1997 questionnaire.

łIncomplete data: at baseline (1987): educational level ( $n=60346)$ and living alone ( $n=60860)$; at second questionnaire (1997): leisure time physical activity level $(n=34609)$, smoking status $(n=38143)$, and cortisone use $(n=27011)$. 
Table 2| Absolute rates and age and multivariable adjusted hazard ratios of all cause and cardiovascular mortality by categories of average cumulative intake of total and dietary calcium

\begin{tabular}{|c|c|c|c|c|}
\hline \multirow[b]{2}{*}{ Variables } & \multicolumn{4}{|c|}{ Calcium intake (mg/day) } \\
\hline & $<600$ & $600-999$ & 1000-1399 & $\geq 1400$ \\
\hline \multicolumn{5}{|c|}{ Analyses based on dietary calcium intake } \\
\hline Person years at risk & 50150 & 743403 & 292899 & 8428 \\
\hline \multicolumn{5}{|l|}{ All causes: } \\
\hline No of deaths & 597 & 8011 & 3208 & 128 \\
\hline Rate per 1000 person years $(95 \% \mathrm{Cl})$ & $11.9(11.0$ to 12.9$)$ & $10.8(10.5$ to 11.0$)$ & $11.0(10.6$ to 11.3$)$ & $15.2(12.8$ to 18.1$)$ \\
\hline Age adjusted hazard ratio $(95 \% \mathrm{Cl})$ & $1.60(1.47$ to 1.74$)$ & 1.00 (reference) & 0.93 (0.90 to 0.97 ) & $1.35(1.13$ to 1.60$)$ \\
\hline Adjusted hazard ratio* $(95 \% \mathrm{Cl})$ & $1.38(1.27$ to 1.51$)$ & 1.00 (reference) & 1.00 (0.96 to 1.04$)$ & $1.40(1.17$ to 1.67$)$ \\
\hline \multicolumn{5}{|l|}{ Cardiovascular disease: } \\
\hline No of deaths & 219 & 2576 & 1025 & 42 \\
\hline Rate per 1000 person years $(95 \% \mathrm{Cl})$ & $4.4(3.8$ to 5.0$)$ & $3.5(3.3$ to 3.6$)$ & $3.5(3.3$ to 3.7$)$ & 5.0 (3.7 to 6.7$)$ \\
\hline Age adjusted hazard ratio $(95 \% \mathrm{Cl})$ & 1.90 (1.65 to 2.18$)$ & 1.00 (reference) & $0.93(0.87$ to 1.00$)$ & $1.37(1.01$ to 1.86$)$ \\
\hline Adjusted hazard ratio* $(95 \% \mathrm{Cl})$ & $1.63(1.42$ to 1.87$)$ & 1.00 (reference) & $1.01(0.94$ to 1.09$)$ & 1.49 (1.09 to 2.02$)$ \\
\hline \multicolumn{5}{|l|}{ Ischaemic heart disease: } \\
\hline No of deaths & 113 & 1274 & 515 & 30 \\
\hline Rate per 1000 person years $(95 \% \mathrm{Cl})$ & $2.3(1.9$ to 2.7$)$ & $1.7(1.6$ to 1.8$)$ & $1.8(1.6$ to 1.9$)$ & $3.6(2.5$ to 5.1$)$ \\
\hline Age adjusted hazard ratio $(95 \% \mathrm{Cl})$ & 1.85 (1.53 to 2.25$)$ & 1.00 (reference) & 0.97 (0.87 to 1.07$)$ & 2.01 (1.40 to 2.88$)$ \\
\hline Adjusted hazard ratio* $(95 \% \mathrm{Cl})$ & 1.65 (1.36 to 2.01$)$ & 1.00 (reference) & $1.03(0.93$ to 1.15$)$ & 2.14 (1.48 to 3.09$)$ \\
\hline \multicolumn{5}{|l|}{ Stroke: } \\
\hline No of deaths & 57 & 740 & 297 & 6 \\
\hline Rate per 1000 person years $(95 \% \mathrm{Cl})$ & $1.1(0.9$ to 1.5$)$ & $1.0(0.9$ to 1.1$)$ & $1.0(0.9$ to 1.1$)$ & 0.7 (0.3 to 1.6$)$ \\
\hline Age adjusted hazard ratio $(95 \% \mathrm{Cl})$ & 1.77 (1.35 to 2.32$)$ & 1.00 (reference) & 0.94 (0.82 to 1.07 ) & 0.68 (0.31 to 1.52$)$ \\
\hline Adjusted hazard ratio* $(95 \% \mathrm{Cl})$ & 1.50 (1.14 to 1.97$)$ & 1.00 (reference) & 1.02 (0.89 to 1.17 ) & $0.73(0.33$ to 1.65$)$ \\
\hline \multicolumn{5}{|l|}{ Analyses based on total calcium intake } \\
\hline Person years at risk & 49195 & 705006 & 313628 & 27051 \\
\hline \multicolumn{5}{|l|}{ All causes: } \\
\hline No of deaths & 586 & 7603 & 3405 & 350 \\
\hline Rate per 1000 person years $(95 \% \mathrm{Cl})$ & $11.9(11.0$ to 12.9$)$ & $10.8(10.5$ to 11.0$)$ & $10.9(10.5$ to 11.2$)$ & $12.9(11.7$ to 14.4$)$ \\
\hline Age adjusted hazard ratio $(95 \% \mathrm{Cl})$ & $1.59(1.46$ to 1.73$)$ & 1.00 (reference) & 0.86 (0.82 to 0.89$)$ & $0.72(0.65$ to 0.80$)$ \\
\hline Adjusted hazard ratio* $(95 \% \mathrm{Cl})$ & 1.40 (1.28 to 1.52$)$ & 1.00 (reference) & 1.03 (0.99 to 1.07 ) & $1.40(1.25$ to 1.57$)$ \\
\hline \multicolumn{5}{|l|}{ Cardiovascular disease: } \\
\hline No of deaths & 217 & 2464 & 1073 & 108 \\
\hline Rate per 1000 person years $(95 \% \mathrm{Cl})$ & $4.4(3.9$ to 5.0$)$ & 3.5 (3.4 to 3.6$)$ & 3.4 (3.2 to 3.6$)$ & 4.0 (3.3 to 4.8$)$ \\
\hline Age adjusted hazard ratio $(95 \% \mathrm{Cl})$ & 1.89 (1.65 to 2.18$)$ & 1.00 (reference) & $0.83(0.78$ to 0.90$)$ & $0.67(0.55$ to 0.81$)$ \\
\hline Adjusted hazard ratio* $(95 \% \mathrm{Cl})$ & $1.65(1.43$ to 1.90$)$ & 1.00 (reference) & 1.04 (0.96 to 1.12$)$ & $1.51(1.23$ to 1.84$)$ \\
\hline \multicolumn{5}{|l|}{ Ischaemic heart disease: } \\
\hline No of deaths & 111 & 1225 & 533 & 63 \\
\hline Rate per 1000 person years $(95 \% \mathrm{Cl})$ & $2.3(1.9$ to 2.7$)$ & $1.7(1.6$ to 1.8$)$ & $1.7(1.6$ to 1.9$)$ & 2.3 (1.8 to 3.0$)$ \\
\hline Age adjusted hazard ratio $(95 \% \mathrm{Cl})$ & 1.82 (1.50 to 2.22$)$ & 1.00 (reference) & 0.86 (0.78 to 0.95$)$ & $0.83(0.65$ to 1.08$)$ \\
\hline Adjusted hazard ratio* $(95 \% \mathrm{Cl})$ & 1.65 (1.35 to 2.01$)$ & 1.00 (reference) & 1.05 (0.94 to 1.16$)$ & $1.90(1.45$ to 2.49$)$ \\
\hline \multicolumn{5}{|l|}{ Stroke: } \\
\hline No of deaths & 57 & 709 & 313 & 21 \\
\hline Rate per 1000 person years $(95 \% \mathrm{Cl})$ & $1.2(0.9$ to 1.5$)$ & $1.0(0.9$ to 1.1$)$ & $1.0(0.9$ to 1.1$)$ & 0.8 (0.5 to 1.2$)$ \\
\hline Age adjusted hazard ratio $(95 \% \mathrm{Cl})$ & 1.78 (1.36 to 2.34$)$ & 1.00 (reference) & 0.84 (0.73 to 0.96$)$ & $0.44(0.29$ to 0.68$)$ \\
\hline Adjusted hazard ratio* $(95 \% \mathrm{Cl})$ & $1.53(1.17$ to 2.01$)$ & 1.00 (reference) & 1.04 (0.90 to 1.19$)$ & $0.96(0.61$ to 1.50$)$ \\
\hline
\end{tabular}

Calcium intake by categories refers to cumulative average intake in cohort. 
Table 2 (continued)

\begin{tabular}{|c|c|c|c|c|}
\hline \multirow[b]{2}{*}{ Variables } & \multicolumn{4}{|c|}{ Calcium intake (mg/day) } \\
\hline & $<600$ & $600-999$ & $1000-1399$ & $\geq 1400$ \\
\hline
\end{tabular}

*Adjusted for age, total energy and vitamin D intake, a healthy dietary pattern, body mass index, height, living alone, educational level, physical activity level, smoking status, use of calcium containing supplements, and Charlson's comorbidity index. 
Table 3 | Absolute rates and age and multivariable adjusted hazard ratios of all cause mortality by categories of average cumulative intake of dietary calcium by calcium supplement use

\begin{tabular}{|c|c|c|c|c|}
\hline \multirow[b]{2}{*}{ Variables } & \multicolumn{4}{|c|}{ Dietary calcium intake (mg/day) } \\
\hline & $<600$ & $600-999$ & 1000-1399 & $\geq 1400$ \\
\hline \multicolumn{5}{|l|}{ No supplement use: } \\
\hline No of deaths & 580 & 7324 & 2842 & 112 \\
\hline Person years at risk & 44736 & 617437 & 237108 & 7067 \\
\hline Rate per 1000 person years $(95 \% \mathrm{Cl})$ & $13.0(12.0$ to 14.1$)$ & $11.9(11.6$ to 12.1$)$ & $12.0(11.6-12.4)$ & $15.8(13.2-19.1)$ \\
\hline Age adjusted hazard ratio $(95 \% \mathrm{Cl})$ & $1.53(1.41$ to 1.67$)$ & $1.00(1.00$ to 1.00$)$ & 0.95 (0.91 to 0.99$)$ & 1.30 (1.08 to 1.56$)$ \\
\hline Adjusted hazard ratio* $(95 \% \mathrm{Cl})$ & $1.43(1.32$ to 1.56$)$ & $1.00(1.00$ to 1.00$)$ & 0.94 (0.90 to 0.99$)$ & $1.17(0.97$ to 1.41$)$ \\
\hline \multicolumn{5}{|l|}{$\begin{array}{l}\text { Use of any type of calcium containing } \\
\text { supplement: }\end{array}$} \\
\hline No of deaths & 17 & 687 & 366 & 16 \\
\hline Person years at risk & 5414 & 125966 & 55791 & 1361 \\
\hline Rate per 1000 person years $(95 \% \mathrm{Cl})$ & $3.1(2.0$ to 5.1$)$ & $5.5(5.1$ to 5.9$)$ & $6.6(5.9$ to 7.3$)$ & $11.8(7.2$ to 19.2$)$ \\
\hline Age adjusted hazard ratio $(95 \% \mathrm{Cl})$ & $1.45(0.90$ to 2.35$)$ & $1.00(1.00$ to 1.00$)$ & $0.97(0.85$ to 1.10$)$ & 1.85 (1.13 to 3.03$)$ \\
\hline Adjusted hazard ratio* $(95 \% \mathrm{Cl})$ & $1.17(0.72$ to 1.89$)$ & $1.00(1.00$ to 1.00$)$ & 0.91 (0.80 to 1.04$)$ & 1.51 (0.91 to 2.50$)$ \\
\hline \multicolumn{5}{|l|}{ Use of calcium tablets } \\
\hline No of deaths & 2 & 225 & 107 & 7 \\
\hline Person years at risk & 1820 & 32120 & 13506 & 380 \\
\hline Rate per 1000 person years $(95 \% \mathrm{Cl})$ & $1.1(0.3$ to 4.4$)$ & $7.0(6.1$ to 8.0$)$ & $7.9(6.6$ to 9.6$)$ & $18.4(8.8$ to 38.6$)$ \\
\hline Age adjusted hazard ratio $(95 \% \mathrm{Cl})$ & $0.59(0.15$ to 2.36$)$ & $1.00(1.00$ to 1.00$)$ & $0.87(0.69$ to 1.10$)$ & 2.65 (1.25 to 5.64$)$ \\
\hline Adjusted hazard ratio* $(95 \% \mathrm{Cl})$ & $0.49(0.12$ to 2.01$)$ & $1.00(1.00$ to 1.00$)$ & $0.78(0.61$ to 0.99$)$ & 2.57 (1.19 to 5.55$)$ \\
\hline
\end{tabular}

Calcium intake by categories refers to cumulative average intake in cohort.

*Adjusted for age, total energy and vitamin D intake, a healthy dietary pattern, body mass index, height, living alone, educational level, physical activity level, smoking status, and Charlson's comorbidity index. 


\section{Figures}

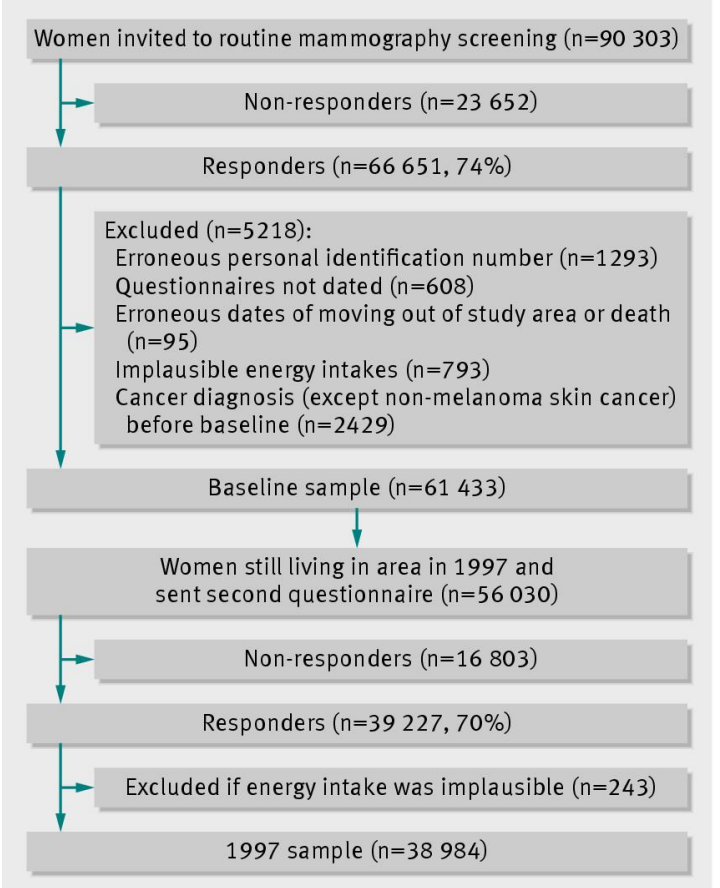

Fig 1 Study samples in Swedish mammography cohort 

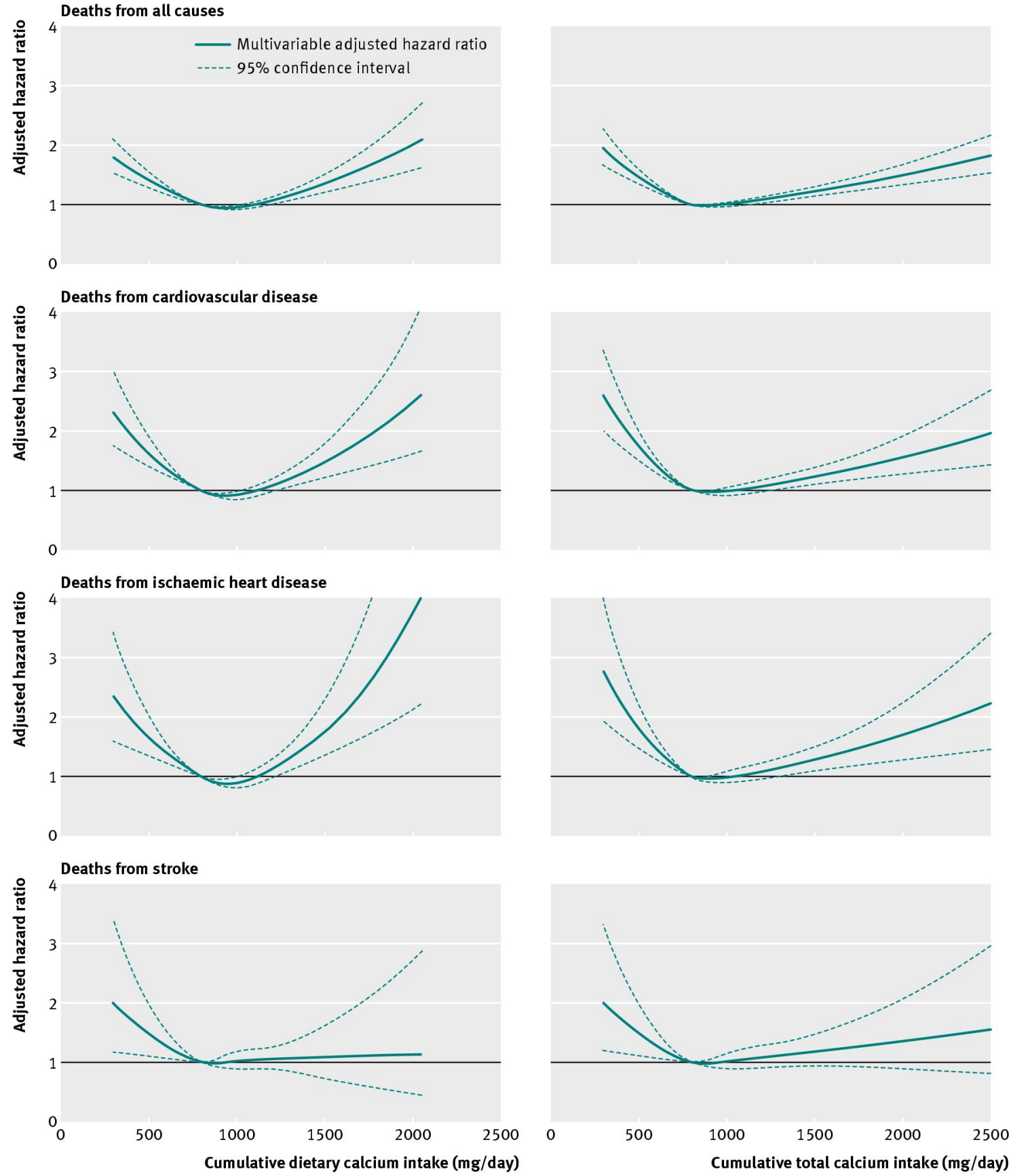

Fig 2 Multivariable adjusted spline curves for relation between cumulative average of dietary and total calcium intake with time to death from all causes, cardiovascular disease, ischaemic heart disease, and stroke. *Adjusted for age, total energy and vitamin D intake, healthy dietary pattern, body mass index, height, living alone, educational level, physical activity level, smoking status, use of calcium containing supplements, and score on Charlson comorbidity index. Reference value for estimation was set at $800 \mathrm{mg}$, which corresponds to the Swedish recommended level of calcium intake for women older than 50 years. The upper confidence limit for ischaemic heart disease is truncated at calcium intake levels higher than about 1800 mg/day 